\section{PROGRAMAS DE PÓS-GRADUAÇÃO STRICTO SENSUEM EDUCAÇÃO FÍSICA NO BRASIL: DIVERSIDADES EPISTEMOLÓGICAS NA SUBÁREA PEDAGÓGICA}

\author{
REGULAR GRADUATE PROGRAMS IN PHYSICAL EDUCATION IN BRAZIL: \\ EPISTEMOLOGICAL DIVERSITIES IN THE PEDAGOGICAL SUBAREA
}

PROGRAMAS DE POSGRADO STRICTO SENSU EN EDUCACIÓN FÍSICA EN BRASIL: DIVERSIDADES EPISTEMOLÓGICAS EN LA SUBÁREA PEDAGÓGICA

Leonardo do Couto Gomes*, Heitor Luiz Furtado*, Marcílio Barbosa Mendonça de Souza Junior**, Marcelo Moraes e Silva*
Palavras chave:

Programas de pós-graduação. Educação Física. Ensino.
Resumo: O presente artigo objetivou mapear as diversidades epistemológicas na subárea pedagógica nos programas de pós-graduação em Educação Física das universidades brasileiras. Para isso foi realizado um estudo exploratório descritivo, tendo como fontes de dados a Plataforma Sucupira, Currículo Lattes e as páginas online dos programas. Foram encontrados 36 programas, com um corpo de 807 professores credenciados. Concluise a existência de um crescente e significativo aumento no número dos programas e docentes vinculados à subárea pedagógica, com a presença de uma heterogeneidade epistemológica nesta subárea, apesar de se constar uma predominância hegemônica da vertente biodinâmica nos programas de pós-graduação em Educação Física no Brasil.
Keywords: Postgraduate Programs. Physical Education. Teaching.
Abstract: This article mapped epistemological diversities in the pedagogical subarea of Physical Education graduate programs at Brazilian universities. A descriptive exploratory study was conducted, using the Sucupira Platform, the Lattes Curriculum and the programs' websites as data sources. We found 36 programs, with 807 registered professors. The findings point out that there is growing and significant increase in the number of programs and professors linked to the pedagogical subarea, which is epistemologically heterogeneous, although there is a hegemonic predominance of the Biodynamic component in graduate programs in Physical Education in Brazil.

Palabras clave: Programas de Posgrado. Educación Física. Enseñanza.
Resumen: El presente artículo objetivó mapear las diversidades epistemológicas en la subárea pedagógica en los programas de posgrado en Educación Física de las universidades brasileñas. Para ello se realizó un estudio exploratorio descriptivo que tuvo como fuente de datos la Plataforma Sucupira, Currículo Lattes y las páginas en línea de los programas. Se encontraron 36 programas, con un cuerpo de 807 profesores acreditados. Se concluye la existencia de un creciente y significativo aumento en el número de programas y docentes vinculados a la subárea pedagógica, con la presencia de una heterogeneidad epistemológica en esta subárea, a pesar de que se constata una predominancia hegemónica de la vertiente Biodinámica en los Programas de Posgrado en Educación Física en Brasil.
*Universidade Federal do Paraná. Curitiba, PR, Brasil.

E-mail: leo gomes.97@ hotmail.com; heitorluizfurtado@ hotmail.com; moraes_marc@yahoo.com.br

**Universidade de Pernambuco. Recife PE, Brasil.

E-mail: marciliosouzajr@ hotmail.com

Recebido em: 04-07-2018

Aprovado em: 18-02-2018

Publicado em: 29-03-2019

DOI

https://doi.org/10.22456/1982-8918.84501

(c) (i) () Licence 


\section{INTRODUÇÃO}

No final da década de 1970, no contexto do enfraquecimento da ditadura militar brasileira e do início do processo de redemocratização do Brasil, surgiu na área da Educação Física um interesse por aportes teóricos amparados nas matrizes das Ciências Humanas. Tal aproximação visava compreender os objetos de pesquisa da área para além dos fatores biológicos fundados na matriz das Ciências Naturais (BRACHT, 1999; FERON; MORAES E SILVA, 2007).

Bracht (1999) e Corrêa et al. (2014) apontam como principal elemento de mudança 0 contato que alguns intelectuais da Educação Física tiveram com o debate pedagógico brasileiro das décadas de 1970 e 1980. Bastos, Sá e Rocco Júnior (2017) indicam que nesse período surgiram os primeiros programas de pós-graduação stricto sensu em Educação Física no país: Universidade de São Paulo (1977) e Universidade Federal de Santa Maria (1979).

A consequência dessa movimentação ocorrida nos anos de 1980 foi o surgimento de várias formas de pensar a Educação Física, culminando com um intenso debate entre os representantes de cada uma das matrizes epistemológicas (BRACHT,1999; FERON; MORAES E SILVA, 2007). Desde então, "novos horizontes" foram vislumbrados e "acirrados" debates foram travados, criando com isso uma grande diversidade no fazer científico em Educação Física no Brasil.

A partir desse período acirram-se dicotomias entre as Ciências Naturais e as Ciências Humanas, potencializando assim um grande conflito na área, inclusive, disputas de espaços e legitimações nas universidades, programas de pós-graduação, linhas de pesquisa e na concorrência por recursos junto aos órgãos de fomento (FERON; MORAES E SILVA, 2007; RIGO; RIBEIRO; HALLAL, 2011; MORAES E SILVA et al. 2017).

Diante desse cenário o presente artigo se propõe a realizar um mapeamento dos programas de pós-graduação em Educação Física no Brasil, lançando um olhar específico sobre a subárea pedagógica. Neste sentido, busca-se responder as seguintes indagações: como se configura a subárea pedagógica dentro dos programas de pós-graduação em Educação Física no Brasil? Quais os eixos temáticos de pesquisa realizados por esta subárea dentro dos referidos programas?

\section{METODOLOGIA}

Este estudo se caracterizou como exploratório-descritivo. Gil (1999) argumenta que a pesquisa exploratória se caracteriza por oferecer um olhar mais amplo perante o fenômeno estudado, ampliando as informações sobre 0 assunto e aprofundando os conceitos sobre a temática estudada. $\mathrm{O}$ autor ainda lembra que a descritiva condiz com as características de uma determinada amostra, buscando evidenciar fatos, opiniões e comportamento existentes no grupo analisado.

Para operacionalizar a presente pesquisa, realizaram-se buscas em veículos online, em especial na Plataforma Sucupira e no Currículo Lattes, em setembro de 2017. Selecionaramse para compor o escopo da presente investigação os 807 docentes credenciados nos 36 programas de pós-graduação em Educação Física. Destes foram encontrados 191 docentes envolvidos de algum modo com a investigações relacionadas à vertente pedagógica. 
Catalogaram-se os docentes em uma planilha eletrônica contendo as seguintes informações: 1) distribuição dos programas por conceito de avaliação Capes; 2) distribuição dos programas por unidade federativa; 3 ) classificação da subárea baseada na sugestão de Manoel e Carvalho (2011), dividida em Biodinâmica, Sociocultural e Pedagógica; 4) categorização das pesquisas por eixo temático.

$\mathrm{Na}$ classificação dos eixos temáticos foram criadas categorias que dessem conta de agrupar as principais abordagens de pesquisa dos docentes. Tais informações foram retiradas dos projetos de pesquisa ativos e registrados pelos pesquisadores em seus Currículo Lattes. Classificaram-se os docentes dentro dos seguintes eixos temáticos:

a) Educação Física Escolar: ênfase na Educação Física enquanto disciplina presente nos processos de escolarização, componente curricular pertencente ao currículo da educação básica contemplando educação infantil, ensino fundamental e médio;

b) Esporte Educacional: foco nas práticas sociais realizadas em contextos além da escola, como clubes e organizações não governamentais, versando sobre a aproximação do esporte a um caráter educacional com intuito de desenvolver através dos esportes valores formativos;

c) Formação de Professores: relacionado aos aspectos dos processos de formação docente nos diversos âmbitos da Educação Física, sejam eles na escola e/ou em outros espaços da intervenção profissional, assim como em outros espaços formais como a universidade e a pós-graduação;

d) Aprendizagem Motora/Pedagogia do Esporte: realça aos aspectos relacionados à aprendizagem motora, crescimento motor e seus desdobramentos para o campo acadêmico/ científico da Educação Física, relacionados principalmente à iniciação esportiva, bem como enfoques na aproximação entre o esporte e a pedagogia, especialmente no que concerne a discussões acerca dos elementos didáticos das práticas pedagógicas para o ensino do Esporte.

Os dados obtidos foram apresentados a partir da análise de tendência central, por meio das frequências absoluta e relativa, sendo esses contrastados com a literatura.

\section{RESULTADOS E DISCUSSÕES}

A Educação Física, conforme lembram Rigo, Ribeiro e Hallal (2011), está inserida na Área 21 da Capes, juntamente com a Fisioterapia, Fonoaudiologia e Terapia Ocupacional. Atualmente a área de Educação Física conta com 807 docentes distribuídos em 36 programas de pós-graduação, conforme pode ser visualizado na tabela na próxima página.

De acordo com o último relatório de avaliação da Capes (2013-2017), produzido pela diretoria de avaliação da Área 21, a subárea Educação Física possui elevada quantidade de cursos com notas três e quatro, alguns conceitos cinco e apenas três com as avaliações mais elevadas seis e sete. Ao comparar tais dados com o relatório avaliativo anterior (triênio de 2013$), 43,69 \%$ dos programas mantiveram suas notas, $15,24 \%$ subiram seus conceitos e apenas 4,7\% diminuíram suas notas (CAPES, 2017), o que denota certa consolidação e amadurecimento da área de um período avaliativo ao outro. 
Tabela 1 - Número de docentes por programa

\begin{tabular}{|c|c|c|c|}
\hline Programas & Docentes & Conceito Capes & Cursos \\
\hline PROEF & 61 & 3 & M \\
\hline UEL/UEM & 45 & 4 & $M / D^{*}$ \\
\hline UNESP/RC & 40 & 5 & $M / D$ \\
\hline USP & 39 & 7 & $M / D$ \\
\hline UNICAMP & 37 & 4 & $M / D$ \\
\hline UNB & 31 & 4 & $M / D$ \\
\hline UERJ & 30 & 4 & $M / D$ \\
\hline UFSC & 30 & 5 & $M / D$ \\
\hline UFRGS & 29 & 6 & $M / D$ \\
\hline UDESC & 26 & 4 & $M / D$ \\
\hline USP/CAT & 25 & 3 & M \\
\hline UFMG & 24 & 5 & $M / D$ \\
\hline UPE/UFPB & 23 & 4 & $M / D$ \\
\hline UFJF/UFV & 22 & 5 & $M / D$ \\
\hline UFES & 22 & 4 & $M / D$ \\
\hline UFPR & 20 & 6 & $M / D$ \\
\hline UFPEL & 19 & 4 & $M / D$ \\
\hline UFRJ & 18 & 3 & M \\
\hline UFTM & 18 & 3 & M \\
\hline UFMT & 18 & 3 & M \\
\hline UNIMEP/CMH & 18 & 4 & $M / D$ \\
\hline USP/RP & 17 & 3 & M \\
\hline UFRN & 17 & 3 & M \\
\hline UCB & 16 & 4 & $M / D$ \\
\hline UNIFESP & 16 & 4 & $M / D$ \\
\hline UFPE & 16 & 3 & M \\
\hline UFSM & 16 & 4 & M \\
\hline UNIVASF & 16 & 3 & M \\
\hline UFMA & 15 & 3 & M \\
\hline FUFSE & 14 & 3 & M \\
\hline USJT & 14 & 4 & M \\
\hline UNIVERSO & 13 & 3 & M \\
\hline UNOPAR & 12 & 4 & M \\
\hline UTFPR & 12 & 3 & M \\
\hline UNICSUL * & 10 & 3 & M \\
\hline UNIMEP/EDF & 8 & 4 & $M$ \\
\hline Total geral & 807 & & \\
\hline
\end{tabular}

Fonte: os autores

${ }^{*} \mathrm{M}$ se refere a programas que contêm apenas mestrado e $M / D$ a programas que apresentam mestrado e doutorado. ** Curso em processo de desativação

Nota-se também que a área é bastante caracterizada por programas de natureza acadêmica (92,7\% do total de programas), enquanto os profissionais ainda estão em fase 
inicial $(7,5 \%)^{1}$. Dentre os programas acadêmicos, observa-se que aproximadamente a metade $(52,2 \%)$ oferta doutorado. As notas seis e sete, (USP- São Paulo, UFPR e UFRGS) foram reservadas exclusivamente para os programas com doutorado que obtiveram conceito "Muito Bom" em todos os quesitos da avaliação Capes: proposta do programa; corpo docente; corpo discente; teses e dissertações; produção intelectual; e inserção social (CAPES, 2017).

No que concerne aos conceitos atribuídos aos programas, a Tabela 1 também apresenta as instituições que apresentaram os maiores números de docentes de forma absoluta: PROEF² (61); o programa associado UEL/UEM (45); o da Unesp/RC (41), USP-São Paulo (40); Unicamp (36); seguidos de UNB e UFSC (30). O fato do PROEF possuir o maior número de docentes se deve pelo motivo de ser um programa em rede no qual diversos pesquisadores, inclusive credenciados em outros programas, compõem o corpo docente. Os quatro cursos com os menores números de docentes são os seguintes: UNIVERSO (13), UFTPR (12), Unopar (11) e UNICSUL (11).

Ao tentar fazer uma relação entre os números absolutos de docentes e os conceitos atribuídos aos programas, não foi possível estabelecer uma relação direta entre cursos mais bem avaliados e o número elevado de docentes credenciados nos programas. Tal fato aponta para uma diversidade no interior de cada curso, como, por exemplo, os programas considerados de excelência como os da USP, UFRGS e UFPR que possuem 39, 29 e 20 docentes respectivamente, da mesma forma como programas avaliados com nota cinco (Unesp, 40 docentes; UFSC, 30 docentes; UFMG, 24; e UFJF/UFV, 22 docentes) também apresentam números muito diferentes entre si.

No intento de refletir acerca das subáreas em que os docentes desenvolvem suas pesquisas, tomou-se como parâmetro a classificação sugerida por Manoel e Carvalho (2011, p.392), que categorizam as pesquisas em Educação Física em três subáreas:

A biodinâmica compreende as atividades de pesquisa dentro de subdisciplinas como bioquímica do exercício, biomecânica, fisiologia do exercício, controle motor, aprendizagem e desenvolvimento motor, além de alguns campos aplicados, como nutrição esportiva e treinamento físico e desportivo. As linhas de pesquisa na biodinâmica são orientadas pelas ciências naturais [...] A subárea sociocultural trata de temas como esporte, práticas corporais e atividade física nas perspectivas da sociologia, da antropologia, da história e da filosofia. A subárea pedagógica investiga questões relativas à formação de professores, ao desenvolvimento curricular, aos métodos de ensino e à pedagogia do esporte, além de tratar de aspectos metodológicos, sociais, políticos e filosóficos da educação. As subáreas sociocultural e pedagógica definem suas linhas de investigação orientadas pelas ciências sociais e humanas (MANOEL; CARVALHO, 2011, p.392).

A classificação proposta se mostra extremamente complexa e, por vezes, seus enquadramentos foram dificeis de se aplicar à pesquisa, devido à diversidade e/ou mesmo ao dinamismo dos docentes nas temáticas de seus estudos. Nesse sentido, alguns pesquisadores não poderiam ser categorizados em apenas uma única subárea, pois realizam suas pesquisas alicerçados em subáreas distintas.

\footnotetext{
1 Ressalta-se que tais números representam o Programa de pós-graduação da Universidade Norte do Paraná (Unopar) e do Mestrado profissional em Educação Física em rede nacional (PROEF).

20 PROEF é um Programa de Mestrado Profissional em rede na área da Educação Física Escolar coordenado pela UNESP (DARIDO GONZÁLEZ, 2015), contando com 14 instituições parceiras. O presente programa se encontra em funcionamento, tendo sua aula inaugural em 13/04/18. Disponível em: http:/www.capes.gov.br/sala-de-imprensa/noticias/8860-mestrado-profissional-em-educacao-fisica-em-redenacional-tem-aula-inaugural
} 
Tabela 2 - Docentes por subárea

\begin{tabular}{lcc}
\hline SUBÁREAS & DOCENTES & $\%$ \\
\hline BIODINÂMICA & 539 & $66,79 \%$ \\
PEDAGÓGICA/SOCIOCULTURAL & 113 & $14,00 \%$ \\
SOCIOCULTURAL & 68 & $8,43 \%$ \\
PEDAGÓGICA & 55 & $6,82 \%$ \\
BIODINÂMICA/PEDAGÓGICA & 23 & $2,85 \%$ \\
BIODINÂMICA/SOCIOCULTURAL & 9 & $1,12 \%$ \\
\hline TOTAL GERAL & $\mathbf{8 0 7}$ & $\mathbf{1 0 0 , 0 0 \%}$ \\
\hline
\end{tabular}

Fonte: os autores

Os resultados corroboram os dados levantados por Manoel e Carvalho (2011), que também apontam a predominância da Biodinâmica no interior dos programas. Após o trabalho empreendido percebe-se que 571 docentes (70,76\%) utilizam em suas pesquisas elementos amparados na Biodinâmica, ainda que em alguns casos haja certo diálogo com as humanidades. Essa predominância da Biodinâmica se justifica, conforme aponta Rigo, Ribeiro e Hallal (2011), pela trajetória epistemológica e constituição científica da área da Educação Fisica fortemente relacionada com as Ciências Naturais. Entretando, Bracht (1999) e Feron e Moraes e Silva (2007) enfatizam que os discursos amparados nas Ciências Humanas começaram a circular fortemente na Educação Física brasileira a partir da década de 1980, buscando propor novos olhares para os diversos objetos de estudo da Educação Fisica, para um olhar além de um enfoque marcado por um discurso biológico. Nesse sentido, considera-se relevante apontar a existência de $236(29,25 \%)$ docentes credenciados nos programas, realizando pesquisas com aporte teórico nas humanidades. Destaca-se também que 32 docentes (3,97\%) desenvolvem seus estudos em matrizes epistemológicas situadas tanto nas Ciências Naturais como nas Ciências Humanas.

Como visto, os pesquisadores que se dedicam à subárea pedagógica se restringem a 55 investigadores (6,82\%). Existe um número considerável de docentes (113 pesquisadores-14\%) que realizam pesquisas tanto na subárea sociocultural como na pedagógica (14\%). Fato justificavél principalmente pela aproximação epistemológica entre as subáreas. A aproximação dos professores da área pedagógica com a sociocultural se dá basicamente pelos eixos temáticos Educação Física Escolar, Esporte Educacional e/ou Formação de Professores. Por sua vez, os da biodinâmica com a pedagógica ocorrem pelos eixos da Aprendizagem Motora e Pedagogia do Esporte.

Após a classifição geral da distribuição dos docentes nas subáreas, se faz necessário apresentar como cada programa de pós-graduação está organizado quanto à distribuição de seus docentes dentro de cada subárea e seus valores percentuais comparados ao total geral do número de docentes pertencentes aos programas analisados.

Os dados a seguir (tabela 3) fornecem elementos importantes para a análise de cada programa, sinalizando para a existência de diversidades epistemológicas no interior deles. Alguns dos programas têm foco exclusivo na Biodinâmica, como os da Unopar, UNICSUL, UFSE e UFMG, outros com forte predominância como, por exemplo, os da Udesc, Unifesp, UFPE e da UFJF/UFV. Quando refere-se à vertente sociocultural não foi possível identificar 
nenhum programa com predomínio desta subárea, porém alguns programas destacam-se, tais como 0 da UNIVERSO (38,46\%), USP/CAT (24\%), UFPR (20\%), UFRN $(17,65 \%)$; UFGRS $(17,24 \%)$ e o progama da Unicamp $(16,22 \%)$.

Tabela 3 - Docentes por subárea nos programas

\begin{tabular}{|c|c|c|c|c|c|c|c|}
\hline PROGRAMAS & PED & PED/SOC & BIOD/PED & BIOD & BIOD/SOC & SOC & TOTAL \\
\hline PROEF & $34,43 \%$ & $65,57 \%$ & $0,00 \%$ & $0,00 \%$ & $0,00 \%$ & $0,00 \%$ & $100,00 \%$ \\
\hline UFES & $13,64 \%$ & $36,36 \%$ & $0,00 \%$ & $31,82 \%$ & $0,00 \%$ & $18,18 \%$ & $100,00 \%$ \\
\hline UFSC & $13,33 \%$ & $13,33 \%$ & $0,00 \%$ & $70,00 \%$ & $0,00 \%$ & $3,33 \%$ & $100,00 \%$ \\
\hline UFSM & $12,50 \%$ & $25,00 \%$ & $0,00 \%$ & $62,50 \%$ & $0,00 \%$ & $0,00 \%$ & $100,00 \%$ \\
\hline UNIMEP/CMH & $11,11 \%$ & $16,67 \%$ & $0,00 \%$ & $66,67 \%$ & $0,00 \%$ & $5,56 \%$ & $100,00 \%$ \\
\hline UFPEL & $10,53 \%$ & $0,00 \%$ & $5,26 \%$ & $73,68 \%$ & $0,00 \%$ & $10,53 \%$ & $100,00 \%$ \\
\hline USP & $10,26 \%$ & $12,82 \%$ & $10,26 \%$ & $51,28 \%$ & $2,56 \%$ & $12,82 \%$ & $100,00 \%$ \\
\hline UNESP/RC & $10,00 \%$ & $5,00 \%$ & $0,00 \%$ & $75,00 \%$ & $2,50 \%$ & $7,50 \%$ & $100,00 \%$ \\
\hline UTFPR & $8,33 \%$ & $0,00 \%$ & $0,00 \%$ & $83,33 \%$ & $0,00 \%$ & $8,33 \%$ & $100,00 \%$ \\
\hline UNICAMP & $8,11 \%$ & $8,11 \%$ & $10,81 \%$ & $56,76 \%$ & $0,00 \%$ & $16,22 \%$ & $100,00 \%$ \\
\hline UFRGS & $6,90 \%$ & $10,34 \%$ & $3,45 \%$ & $58,62 \%$ & $3,45 \%$ & $17,24 \%$ & $100,00 \%$ \\
\hline UFRN & $5,88 \%$ & $17,65 \%$ & $0,00 \%$ & $58,82 \%$ & $0,00 \%$ & $17,65 \%$ & $100,00 \%$ \\
\hline UFMT & $5,56 \%$ & $16,67 \%$ & $5,56 \%$ & $66,67 \%$ & $0,00 \%$ & $5,56 \%$ & $100,00 \%$ \\
\hline UFTM & $5,56 \%$ & $5,56 \%$ & $5,56 \%$ & $83,33 \%$ & $0,00 \%$ & $0,00 \%$ & $100,00 \%$ \\
\hline UEL/UEM & $4,44 \%$ & $11,11 \%$ & $2,22 \%$ & $77,78 \%$ & $0,00 \%$ & $4,44 \%$ & $100,00 \%$ \\
\hline UPE/UFPB & $4,35 \%$ & $13,04 \%$ & $0,00 \%$ & $73,91 \%$ & $0,00 \%$ & $8,70 \%$ & $100,00 \%$ \\
\hline UNB & $3,23 \%$ & $16,13 \%$ & $0,00 \%$ & $64,52 \%$ & $3,23 \%$ & $12,90 \%$ & $100,00 \%$ \\
\hline UERJ & $0,00 \%$ & $23,33 \%$ & $10,00 \%$ & $56,67 \%$ & $0,00 \%$ & $10,00 \%$ & $100,00 \%$ \\
\hline UFPR & $0,00 \%$ & $15,00 \%$ & $0,00 \%$ & $65,00 \%$ & $0,00 \%$ & $20,00 \%$ & $100,00 \%$ \\
\hline UNIVASF & $0,00 \%$ & $12,50 \%$ & $0,00 \%$ & $75,00 \%$ & $0,00 \%$ & $12,50 \%$ & $100,00 \%$ \\
\hline UNIMEP/EDF & $0,00 \%$ & $12,50 \%$ & $0,00 \%$ & $87,50 \%$ & $0,00 \%$ & $0,00 \%$ & $100,00 \%$ \\
\hline USP/RP & $0,00 \%$ & $11,76 \%$ & $0,00 \%$ & $76,47 \%$ & $0,00 \%$ & $11,76 \%$ & $100,00 \%$ \\
\hline USP/CAT & $0,00 \%$ & $8,00 \%$ & $4,00 \%$ & $56,00 \%$ & $8,00 \%$ & $24,00 \%$ & $100,00 \%$ \\
\hline UNIVERSO & $0,00 \%$ & $7,69 \%$ & $7,69 \%$ & $46,15 \%$ & $0,00 \%$ & $38,46 \%$ & $100,00 \%$ \\
\hline USJT & $0,00 \%$ & $7,14 \%$ & $7,14 \%$ & $71,43 \%$ & $7,14 \%$ & $7,14 \%$ & $100,00 \%$ \\
\hline UFRJ & $0,00 \%$ & $5,56 \%$ & $0,00 \%$ & $88,89 \%$ & $5,56 \%$ & $0,00 \%$ & $100,00 \%$ \\
\hline UFJF/UFV & $0,00 \%$ & $4,55 \%$ & $4,55 \%$ & $86,36 \%$ & $0,00 \%$ & $4,55 \%$ & $100,00 \%$ \\
\hline UDESC & $0,00 \%$ & $0,00 \%$ & $0,00 \%$ & $96,15 \%$ & $0,00 \%$ & $3,85 \%$ & $100,00 \%$ \\
\hline UFMG & $0,00 \%$ & $0,00 \%$ & $0,00 \%$ & $100,00 \%$ & $0,00 \%$ & $0,00 \%$ & $100,00 \%$ \\
\hline UCB & $0,00 \%$ & $0,00 \%$ & $0,00 \%$ & $87,50 \%$ & $0,00 \%$ & $12,50 \%$ & $100,00 \%$ \\
\hline UNIFESP & $0,00 \%$ & $0,00 \%$ & $6,25 \%$ & $93,75 \%$ & $0,00 \%$ & $0,00 \%$ & $100,00 \%$ \\
\hline UFPE & $0,00 \%$ & $0,00 \%$ & $0,00 \%$ & $93,75 \%$ & $0,00 \%$ & $6,25 \%$ & $100,00 \%$ \\
\hline UFMA & $0,00 \%$ & $0,00 \%$ & $13,33 \%$ & $80,00 \%$ & $6,67 \%$ & $0,00 \%$ & $100,00 \%$ \\
\hline FUFSE & $0,00 \%$ & $0,00 \%$ & $0,00 \%$ & $100,00 \%$ & $0,00 \%$ & $0,00 \%$ & $100,00 \%$ \\
\hline UNOPAR & $0,00 \%$ & $0,00 \%$ & $0,00 \%$ & $100,00 \%$ & $0,00 \%$ & $0,00 \%$ & $100,00 \%$ \\
\hline UNICSUL & $0,00 \%$ & $0,00 \%$ & $0,00 \%$ & $100,00 \%$ & $0,00 \%$ & $0,00 \%$ & $100,00 \%$ \\
\hline TOTAL & $6,82 \%$ & $14,00 \%$ & $2,85 \%$ & $66,79 \%$ & $1,12 \%$ & $8,43 \%$ & $100,00 \%$ \\
\hline
\end{tabular}


Os programas com o maiores números de docentes classificados exclusivamente na subárea pedagógica são os da PROEF (34,4\%), Ufes (13,64\%), UFSC $(13,33 \%)$, UFSM (12,50\%), Unimep (11,11\%), UFPel (10,53\%) e USP (10,22\%) e Unesp (10\%). A partir da análise dos oito programas com os maiores números de pesquisadores situados na vertente pedagógica, identifica-se que a maioria encontra-se nos programas avaliados com nota quatro (Ufes, UFSM, UFPel e Unimep), dois programas situados na nota cinco (Unesp e UFSC), um programa com nota sete (USP-São Paulo) e um programa com a nota três (PROEF).

O fato do PROEF possuir números mais elevados se dá pelo fato de ser um programa destinado à formação de professores de Educação Física vinculados ao ensino básico, especialmente os atuantes em escolas. O programa oferta a modalidade de mestrado profissional e é realizado por uma rede de Instituições de Ensino Superior, objetivando aprimorar a formação de professores, visando diminuir a lacuna existente entre a esfera acadêmico-científica e a atuação profissional nas escolas brasileiras (DARIDO; GONZALEZ, 2015). Pelo programa ter o enfoque principal na Educação Física Escolar, os dados apresentados acima confirmam a exclusividade de docentes situados na subárea pedagógica e pedagógica/sociocultural, inclusive foram selecionados a participarem do programa justamente por tematizaram a escola e a formação de professores em suas formações acadêmicas.

Torna-se necessário apontar que mesmo com números inferiores na maioria dos programas, os docentes situados na subárea pedagógica atingem porcentagens significativas de forma geral. Se somadas as aproximações da subárea sociocultural e biodinâmica com a pedagógica, o número total de docentes representa $23,67 \%$ do total. No que tange às subáreas da Educação Física, nota-se que existe uma acentuada discrepância entre a subárea biodinâmica em relação à pedagógica e sociocultural. Contudo, este quadro não é algo restrito à Educação Física, visto que tal cenário também é observado em outras áreas de conhecimento, como evidenciado por Nardi (2015) no caso da Matemática.

Considera-se que, apesar do processo de estruturação da esfera científica em Educação Física no Brasil estar alicerçado em perspectivas situadas nas Ciências Naturais (RIGO; RIBEIRO; HALLAL, 2011), e por consequência na subárea biodinâmica (MANOEL; CARVALHO, 2011), os dados atuais apontam para um crescimento e amadurecimento no interior dos programas de discussões com base nas Ciências Humanas. Pelo fato de a entrada de referências teóricas situadas nas humanidades ter sido tardia, comparada com as matrizes científicas das Ciências Naturais, como já bem destacado por Bracht (1999), o campo acadêmico cíentifico da área se constituiu em um primeiro momento marcadamente por uma perspectiva biológica, o que justifica, por exemplo, o predomínio de docentes situados na subárea biodinâmica.

Para um melhor entendimento das distribuições acima mencionadas, se faz necessário um aprofundamento no interior de cada programa, buscando compreender seus processos históricos, suas matrizes e direcionamentos epistemológicos nos quais norteiam suas produções teóricas, não caindo em um determinismo simplista de um enfraquecimento da subárea pedagógica pela não valorização das discussões pedagógicas no interior dos programas de pós-graduação em Educação Física no Brasil.

Os dados encontrados permitem levantar a hipótese de que a subárea pedagógica tem buscado sua valorização, consolidação e permanência num movimento de resistência diante 
supremacia da biodinâmica por dentro da Área 21, pertencente à grande área da Saúde. As dicotomias entre as Ciências da Natureza e Ciências Humanas começam a ser problematizadas, buscando aproximações através de diálogos entre os campos epistemológicos. Entretanto as disputas, legitimações e concorrências no interior dos programas ainda se dão em meio a distribuições desiguais, sendo possivelmente consequência dos processos da constituição histórica da área na esfera científica.

Além de um levantamento geral sobre a distribuição dos docentes nos programas de pós-graduação e o lugar ocupado pela subárea pedagógica nestes espaços, apresentam-se os principais eixos temáticos das pesquisas. Tais categorizações, por sua vez, foram criadas a partir da leitura dos projetos de pesquisa ativos e registrados no Curriculo Lattes dos docentes. O gráfico a seguir apresenta a distribuição dos pesquisadores nesses eixos temáticos.

Gráfico 1 - Principais abordagens da subárea pedagógica

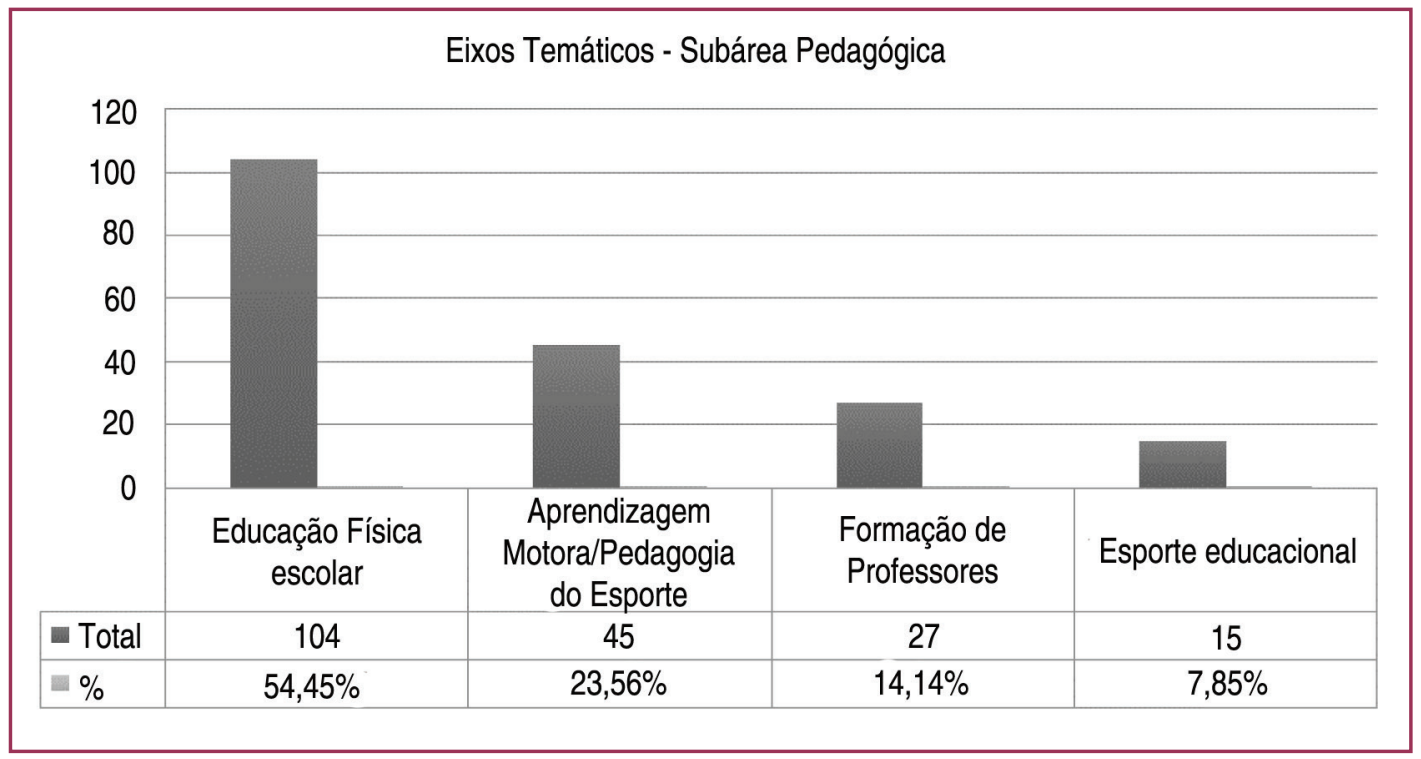

Fonte: os autores

Destaca-se a predominância de discussões relativas à Educação Física Escolar (54,45\%). Fato justificável tendo em vista o papel social, bem como o percurso histórico da Educação Física marcadamente por sua presença dentro da instituição escolar (BRACHT, 2015). Em seguida encontra-se a Aprendizagem Motora/Pedagogia do Esporte (23,56\%). Torna-se importante salientar que a Aprendizagem Motora busca desenvolver pesquisas relativas ao ensino das gestualidades, inclusive em suas dimensões técnicas, situando os enfoques das discussões no controle motor e no desenvolvimento motor.

Por sua vez, Scaglia, Reverdito e Galatti (2014) salientam que é preciso compreender que a Pedagogia é um caminho refletido que leva à construção de conhecimentos, por meio de aprendizagens (motoras, inclusive) e que quando o conteúdo é o esporte torna-se necessário pedagogizá-lo. Para os autores o processo de aproximação entre a Pedagogia e o Esporte deve ser entendido como uma intervenção desenvolvida dentro de um processo de ensinoaprendizagem que leve em conta o aluno em seus processos de ensino-treinamento-competição. Neste sentido, a classificação do eixo temático Aprendizagem Motora/Pedagogia do Esporte realizada neste artigo é uma tentativa de classificação, mesmo sabendo que são definições 
com algumas diferenças. Porém, apesar de possuírem pontos distintos, também apresentam semelhanças, visto que versam sobre o ensino do movimento corporal e do Esporte.

Em terceiro lugar na distribuição nos eixos temáticos encontram-se os docentes que focalizam suas discussões acerca da Formação de Professores (14,14\%). Seus enfoques exploram a relação entre a formação inicial/continuada em Educação Física nos diversos níveis de ensino, seja na educação básica, no ensino superior, ou em outros ambientes formais e não formais de ensino. Farias e Nascimento (2012) indicam que os estudos e reflexões sobre os processos de formação de professores em seus diversos níveis na Educação Física são de fundamental importância na medida em que fornecem elementos ricos de análises, apontando para possíveis desdobramentos nos diversos campos de intervenção profissional.

Por fim, o último eixo temático refere-se ao Esporte Educacional, que representa 7,85\% dos docentes situados na subárea pedagógica. Tal forma de realizar a pesquisa advoga que o esporte é uma importante ferramenta social de educação e transformação social e cultural. González etal. (2014) salientam queé possível reconhecer que a expressão Esporte Educacional é utilizada em pelo menos três diferentes sentidos: conceito teórico, termo técnico da política pública e como um tipo específico de intervenção pedagógica. Como conceito teórico, por vezes frágil e impreciso, parece existir uma ambiguidade tendo em vista que pressupõe a existência de outras manifestações do esporte que não caracterizariam esta possibilidade e que não existe prática social que não transmita princípios e valores. Já em relação ao sentido técnico da política pública, o termo parece ser importante na medida em que marca uma diferenciação entre as manifestações do esporte de rendimento e de participação, o que poderia ocasionar uma melhor distribuição dos recursos e ações governamentais. Por fim, o último sentido, um tipo específico de intervenção, conota o trato do esporte na disciplina escolar de Educação Física e a utilização do esporte não como fim dos processos de intervenção, mas, sim, como meio dos processos educacionais.

Torna-se possível inferir que os docentes alocados na subárea pedagógica, mais precisamente no eixo Esporte Educacional, direcionam suas discussões nas três perspectivas citadas e que para um melhor entendimento da configuração das orientações e dos focos dos trabalhos se faz necessário outro estudo não empreendido no escopo do presente artigo. Enquanto no eixo temático Aprendizagem Motora/Pedagogia do Esporte o foco é a reflexão sobre como ensinar/aprender, seus princípios e estratégias, no de Esporte Educacional as práticas esportivas são tomadas como uma possibilidade de educação. Salientam-se os limites desta classificação tendo em vista que as categorias poderiam ser agrupadas de outra forma e/ou novas subcategorias poderiam ser delas derivadas.

A categorização e a construção dos eixos temáticos dentro da subárea pedagógica auxiliam em uma melhor visualização de como ela vem se organizando, da mesma forma evidenciam quais são as temáticas mais privilegiadas, apontando para uma diversidade epistemológica considerável, visto que mesmo situadas na mesma subárea constroem suas análises e reflexões em caminhos teóricos e epistemológicos bastante heterogêneos e híbridos. O quadro a seguir apresenta como os programas com maior número de docentes na subárea pedagógica e suas possíveis aproximações com as demais subáreas distribuem seus docentes nos eixos temáticos apresentados anteriormente. 
Tabela 4 - Docentes por eixos temáticos da subárea pedagógica e suas aproximações nos sete programas com o maior número de docentes na subárea pedagógica

\begin{tabular}{lccccc}
\hline \multicolumn{1}{c}{ Programas } & $\begin{array}{c}\text { Aprendizagem Motoral } \\
\text { Pedagogia do Esporte }\end{array}$ & $\begin{array}{c}\text { Educação Física } \\
\text { Escolar }\end{array}$ & $\begin{array}{c}\text { Esporte } \\
\text { educacional }\end{array}$ & $\begin{array}{c}\text { Formação de } \\
\text { Professores }\end{array}$ & $\begin{array}{c}\text { Total } \\
\text { geral }\end{array}$ \\
\hline PROEF & 2 & 42 & 5 & 12 & 61 \\
USP-São Paulo & 9 & 2 & 0 & 2 & 13 \\
UFES & 0 & 10 & 0 & 1 & 11 \\
UERJ & 3 & 6 & 1 & 0 & 10 \\
UNICAMP & 8 & 1 & 0 & 1 & 10 \\
UEL/UEM & 1 & 2 & 3 & 2 & 8 \\
UFSC & 5 & 3 & 0 & 0 & 8 \\
\hline Total Geral & $\mathbf{2 8}$ & $\mathbf{6 6}$ & $\mathbf{9}$ & $\mathbf{1 8}$ & $\mathbf{1 2 1}$ \\
\hline \multicolumn{2}{c}{ Fonte: os autores } & & &
\end{tabular}

O PROEF contém 42 professores situados no eixo Educação Física Escolar, seguido de 12 professores com núcleo de discussão na Formação de Professores, cinco professores no Esporte educacional e apenas dois na Aprendizagem Motora/Pedagogia do Esporte. Já na Ufes a distribuição aponta um predomínio quase que total da Educação Física Escolar com dez professores e apenas um no eixo da Formação de Professores.

O programa da USP-São Paulo, por sua vez, apresentou nove professores situados na Aprendizagem Motora/Pedagogia do Esporte; dois docentes na Educação Física Escolar e dois professores na Formação de Professores. Pelos dados apresentados percebe-se um forte predomínio do programa da USP-São Paulo na Aprendizagem Motora. Já o programa da UFSC apresenta cinco docentes classificados na Aprendizagem Motora/Pedagogia do Esporte e três docentes na Educação Física Escolar.

O programa da Unicamp, assim como o da USP-São Paulo, apresenta um predomínio da Aprendizagem Motora/Pedagogia do Esporte, visto que possui oito docentes classificados neste eixo temático. Apenas dois professores foram agrupados na Educação Física Escolar. Porém, diferentemente do programa da USP-São Paulo, que apresentou um predomínio de questões relativas à Aprendizagem Motora, 0 da Unicamp apresenta um enfoque maior nas discussões relativas à Pedagogia do Esporte. Já a UERJ possui cinco pesquisadores situados na Educação Física Escolar. No eixo Aprendizagem Motora/Pedagogia do Esporte contabilizaram-se quatro docentes. E, por fim, apenas um docente aparece no eixo Esporte Educacional.

O programa associado da UEL/UEM tem características diferentes dos demais, pois conta com docentes nos quatro eixos temáticos da subárea pedagógica. 0 com o maior número de docentes é o Esporte Educacional, com três professores. Na Educação Física Escolar encontram-se dois docentes, assim como na abordagem Formação de Professores. Por fim, surge o eixo Aprendizagem Motora/Pedagogia do Esporte, com um professor.

Ao relacionar os cursos de pós-graduação com os maiores números de docentes classificados exclusivamente na vertente pedagógica (sem serem somadas as aproximações com as demais subáreas), os dados se alteram um pouco. Os oito programas com as maiores porcentagens de docentes são: mais uma vez 0 da PROEF, com 21 docentes, destes, 12 inseridos no eixo temático Educação Física Escolar, sete na Formação de Professores, um 
docente no Esporte Educacional e outro Aprendizagem Motora/Pedagogia do Esporte. 0 curso da Ufes, por sua vez, possui três docentes exclusivos da subárea pedagógica, dois deles na Educação Física Escolar e um na Formação de Professores. A UFSC conta com quatro pesquisadores, todos situados no Eixo Temático Aprendizagem Motora/Pedagogia do Esporte. $\mathrm{O}$ quarto programa com os maiores valores percentuais de docentes na vertente é o da Unimep, com dois docentes, ambos situados na Educação Física Escolar, já o da UFPel também tem dois professores e se apresentam conjuntamente na Formação de Professores. O sétimo curso é o da USP-São Paulo, que conta com quatro investigadores, dois destes na Aprendizagem Motora/Pedagogia do Esporte e outros dois na Formação de Professores. Por fim surge o programa da Unesp, também com quatro docentes, todos inseridos na Formação de Professores.

Os dados acima indicam que, mesmo situados dentro da subárea pedagógica e suas aproximações com as demais vertentes, os docentes e suas formas de fazer pesquisa apresentam características e peculiaridades que se traduzem em uma grande diversidade epistemológica em seus fazeres científicos, tanto a nível de diferenciação dos objetos, bem como pelo direcionamento privilegiado e/ou negligenciado dos eixos temáticos apresentados anteriormente. Nota-se que em alguns programas as discussões estão mais situadas no eixo Aprendizagem Motora/Pedagogia do Esporte, outros na Educação Física Escolar, Formação de Professores e/ou Esporte educacional, dependendo, assim, das características internas de cada curso e principalmente dos projetos acadêmicos dos docentes neles inseridos. Uma análise mais detalhada poderia indicar a presença dessas diversidades, e se o olhar dentro de cada eixo temático fosse ainda mais minucioso e acurado, detectariam diferentes referenciais teóricos, matrizes científicas e bases epistemológicas. Contudo, tais questões são elementos para estudos futuros.

\section{CONSIDERAÇÕES FINAIS}

O presente artigo teve como intento fazer um mapeamento dos programas de pósgraduação em Educação Física no Brasil, lançando um olhar específico sobre a subárea pedagógica. $O$ esforço empreendido buscou responder às seguintes questões de pesquisa: como se configura a vertente dentro dos programas de pós-graduação em Educação Física no Brasil? Quais os eixos temáticos de pesquisa realizados por essa subárea dentro dos referidos programas?

Ao analisarem-se os resultados obtidos, percebe-se uma predominância da Biodinâmica no interior dos programas e quando comparada a quantidade absoluta de docentes, os valores ainda são muito distantes da subárea pedagógica. Algo compreensível, tendo em vista a configuração histórica da Educação Física profundamente marcada por um fazer científico situado nas Ciências Naturais. O aparecimento das discussões advindas das Ciências Humanas, conforme salientam Bracht (1999) e Feron e Moraes e Silva (2007), é algo recente, tendo iniciado apenas na década de 1980. Essa entrada posterior, em um campo no qual já se operavam outras formas de fazer ciência, marcadamente em matrizes científicas das Ciências Naturais, pode explicar o predomínio de docentes da Biodinâmica nos programas.

Contudo, apesar da hegemonia evidente da Biodinâmica nos programas, a subárea pedagógica, mesmo que minoritária, encontra espaços nos programas de pós-graduação 
apresentando números e características distintas e singulares. Outro importante elemento levantado, e que foi possível identificar a partir dos dados apresentados, é a existência de uma enorme diversidade epistemológica no interior dos programas que, inclusive, se materializam nas próprias subáreas.

Apesar do predomínio das matrizes das Ciências Naturais e pela ênfase da Biodinâmica no interior dos programas de pós-graduação em Educação Física, a área pedagógica se mantém viva e de certa forma crescente, influenciando o hibridismo, bem como a própria dinâmica das subáreas. Afinal, mesmo dentro da vertente pedagógica, as discussões, os caminhos epistemológicos e as ênfases das pesquisas variam de instituição para instituição, bem como de docente para docente, na medida em que apresentam temáticas e focos de pesquisas distintos, apontando mais uma vez para a diversidade no fazer científico da área. A discussão acerca da pós-graduação em Educação Física no Brasil, notadamente no que se refere às discussões pedagógicas, ainda é algo bastante complexo e por vezes carregado de ranços históricos. Apontar para uma predominância das pesquisas, docentes, linhas e grupos de pesquisa situados na Biodinâmica no interior dos programas parece algo já bastante discutido e evidenciado.

Por fim, reconhece-se que novos horizontes precisam ser traçados, apontando para caminhos que mostrem que a diversidade epistemológica existente na área não a enfraquece e nem a torna menos científica. Surge a necessidade de interpretações e análises das possíveis implicações dos mecanismos avaliativos dos órgãos reguladores da pós-graduação brasileira (Capes), uma vez que somente foram utilizados dados referentes às linhas de pesquisa nas quais os docentes atuam e seus respectivos projetos de pesquisa declarados pelos pesquisadores em seus Currículos Lattes. Acaba-se por reconhecer a necessidade de novos estudos que auxiliem na compreensão desse objeto complexo, identificando as características de cada programa e da forma como cada subárea se relaciona com as produções acadêmicas dos docentes e deus orientados, assim como os processos de orientação desses professores e as bolsas de produtividade. Tal expansão pode ser uma importante saída para melhor compreensão de como os programas de pós-graduação em Educação Física se encontram no Brasil.

\section{REFERÊNCIAS}

BASTOS, Flávia da Cunha; SÁ, Marcia Regina de; ROCCO JUNIOR, Ary José. 40 anos da Pós-graduação da EEFE-USP: sua contribuição para a formação de recursos humanos para a docência no ensino superior. Revista Brasileira de Educação Física e Esporte, v. 31 número especial, p. 89-96, 2017.

BRACHT, Valter. Educação Física \& Ciência: Cenas de um Casamento (In)Feliz. ljuí: UNIJUÍ, 1999.

BRACHT, Valter. Desafios e dilemas da pós-graduação em educação física: conhecimento e especificidade. In: RECHIA, Simone et al. (orgs.). Dilemas e desafios da pós-graduação em Educação Física. ljuí: Ed. UNIJUİ, 2015. p. 109-123. 
CAPES - COORDENAÇÃO DE APERFEIÇOAMENTO DE PESSOAL DE NÍVEL SUPERIOR. Documento da Área de Educação Física - ano 2017. Brasília, DF, 2017.

CORRÊA, Amanda Jorge et al. O Esporte brasileiro entre dilemas epistemológicos: da acusação à busca por absolvição. Revista Brasileira de Ciência e Movimento, v. 22, n. 3, p. 118-125, 2014.

DARIDO, Suraya Cristina; GONZÁLEZ, Fernando Jaime. Pós-Graduação em Educação Física: a proposta do Mestrado Profissional em rede (PROEF). In: RECHIA, Simone et. al. (orgs.). Dilemas e desafios da pós-graduação em Educação Física. ljuí: Ed. Unijuí, 2015. p. 163185.

FARIAS, Gelcemar Oliveira; NASCIMENTO, Juarez Viera. Construção da identidade profissional: metamorfoses na carreira docente em Educação Física. In: NASCIMENTO, Juarez Vieira; FARIAS, Gelcemar Oliveira. (orgs.). Construção da identidade profissional em Educação Física: da formação à intervenção. Florianópolis: Editora da Udesc, 2012. p. 61-79.

FERON, Arthur de Vargas; MORAES E SILVA, Marcelo. A Igreja do "Diabo" e a Produção do Conhecimento na Educação Física. Revista Brasileira de Ciências do Esporte, v. 29, n. 1, p. 107-122, 2007.

GIL, Antonio Carlos. Métodos e técnicas de pesquisa social. São Paulo: Atlas, 1999.

GONZÁLEZ, Fernando Jaime et al. Nas pegadas do esporte educacional. In: MARINHO, Alcyane; NASCIMENTO, Juarez Viera; OLIVEIRA, Amauri Aparecido Bássoli (orgs.). Legados do esporte brasileiro. Florianópolis: Editora da Udesc, 2014. p. 35-43.

MANOEL, Edison José; CARVALHO, Yara Maria. Pós-graduação na educação física brasileira: a atração (fatal) para a biodinâmica. Revista de Educação e Pesquisa, v. 37, n. 2, p. 389-406, 2011.

MORAES E SILVA, Marcelo et al. Pós-graduação em Educação Física: apontamentos sobre o livro "Dilemas e desafios da pós-graduação em Educação Física". Journal of Physical Education, v. 28, n. 1, e2840, 2017.

NARDI, Roberto. A pesquisa em ensino de Ciências e Matemática no Brasil. Ciência \& Educação, v. 21, n. 2, p.1-5, 2015.

RIGO, Luis Carlos; RIBEIRO, Gabriela M.; HALLAL, Pedro C. Unidade na diversidade: desafios para a Educação Física no século XXI. Revista Brasileira de Atividade Física \& Saúde, v. 16, n. 4, p. 339-345, 2011.

SCAGLIA, Alcides J.; REVERDITO, Riller S.; GALATTI, Larissa R.; A contribuição da pedagogia do esporte ao ensino do esporte na escola: tensões e reflexões metodológicas. In: MARINHO, Alcyane; NASCIMENTO, Juarez Vieira; OLIVEIRA, Amauri Aparecido Bássoli (orgs.). Legados do esporte brasileiro. Florianópolis: Editora da Udesc, 2014. p. 45-86.

Apoio:

Bolsa de Iniciação Científica do CNPq 